\title{
Noninvasive Ventilation Outcomes in 2,430 Acute Decompensated Heart Failure Patients: An ADHERE Registry Analysis
}

Thomas A. Tallman, DO, W. Frank Peacock, MD, Charles L. Emerman, MD, Margarita Lopatin, MS, Jamie Z. Blicker, MD, James Weber, MD, Clyde W. Yancy, MD, for the ADHERE Registry

\begin{abstract}
Objectives: Continuous or bilevel positive airway pressure ventilation, called noninvasive ventilation (NIV), is a controversial therapy for acute decompensated heart failure (ADHF). While NIV is considered safe and effective in patients with chronic obstructive pulmonary disease (COPD), clinical trial data that have addressed safety in ADHF patients are limited, with some suggestion of increased mortality. The objective of this study was to assess mortality outcomes associated with NIV and to determine if a failed trial of NIV followed by endotracheal intubation (ETI) (NIV failure) is associated with worse outcomes, compared to immediate ETI.
\end{abstract}

Methods: This was a retrospective analysis of the Acute Decompensated Heart Failure National Registry (ADHERE), which enrolls patients with treatment for, or with a primary discharge diagnosis of, ADHF. The authors compared characteristics and outcomes in four groups: no ventilation, NIV success, NIV failure, and ETI. One-way analysis of variance or Wilcoxon testing was performed for continuous data, and chi-square tests were used for categorical data. In addition, multivariable logistic regression was used to adjust mortality comparisons for risk factors.

Results: Entry criteria were met by 37,372 patients, of which 2,430 had ventilation assistance. Of the ventilation group, 1,688 (69.5\%) were deemed NIV success, $72(3.0 \%)$ were NIV failures, and $670(27.6 \%)$ required ETI. The NIV failure group had the lowest $\mathrm{O}_{2}$ saturation $\left(\mathrm{SaO}_{2}\right)(84 \pm 16 \%)$, compared to either NIV success $(89.6 \pm 10 \%)$ or ETI $(88 \pm 13 \% ; p=0.017)$. ETI patients were more likely to receive vasoactive medications $(\mathrm{p}<0.001)$ than the NIV success cohort. When comparing NIV failures to ETI, there were no differences in treatment during hospitalization ( $\mathrm{p}>0.05)$; other than that the NIV failure group more often received vasodilators $(68.1 \%$ vs. $54.3 \%$; $=0.026)$. In-hospital mortality was $7.9 \%$ with NIV, $13.9 \%$ with NIV failure, and $15.4 \%$ with ETI. After risk adjustment, the mortality odds ratio for NIV failure versus ETI increased to 1.43, although this endpoint was not statistically significant.

Conclusions: In this analysis of ADHF patients receiving NIV to date, patients placed on NIV for ADHF fared better than patients requiring immediate ETI. Patients who failed NIV and required ETI still experienced lower mortality than those initially placed on ETI. Thus, while the ETI group may be more severely ill, starting therapy with NIV instead of immediate ETI will likely not harm the patient. When ETI is required, mortality and length of stay may be adversely affected. Since a successful trial of NIV is associated with improved outcomes in patients with ADHF, application of this therapy may be a reasonable treatment option.

ACADEMIC EMERGENCY MEDICINE 2008; 15:355-362 @ 2008 by the Society for Academic Emergency Medicine

Keywords: noninvasive ventilation, Acute Decompensated Heart Failure National Registry, bilevel positive airway pressure, ventilation, endotracheal intubation

\footnotetext{
From the Department of Emergency Medicine, Cleveland Clinic Foundation (TAT, WFP, JZB), Cleveland, OH; MetroHealth Medical Center, Case Western Reserve University (CLE), Cleveland, OH; Biostatistics, Scios, Inc. (ML), Mountain View, CA; the Department of Emergency Medicine, University of Michigan (JEW), Ann Arbor, MI; Hurley Medical Center (JEW), Flint, MI; and the Baylor Heart and Vascular Institute, Baylor University Medical Center (CWY), Dallas, TX.
}

Received June 25, 2007; revision received November 20, 2007; accepted November 21, 2007.

Dr. Blicker is currently with the Victoria Emergency Physician Associates, Victoria, British Columbia, Canada.

Address for correspondence and reprints: Thomas A. Tallman, DO; e-mail: Tallmat@ccf.org. 
$\mathrm{N}$ oninvasive ventilation (NIV) is an alternative to definitive airway placement in emergency department (ED) patients with acute dyspnea, and while well established as beneficial in acute respiratory syndromes (e.g., chronic obstructive pulmonary disease [COPD]), its value in acute decompensated heart failure (ADHF) is less clearly defined. Many studies examine NIV as part of a generic respiratory syndromes strategy (enrolling patients irrespective of their underlying disease state, e.g., COPD, pneumonia, ADHF), and several meta-analyses ${ }^{1,2}$ have specifically reported on NIV in ADHF. However, to our knowledge, only one ADHF data set describing NIV safety or efficacy includes more than 300 patients. Consequently, safety, clinical outcomes, and mortality rates associated with NIV in ADHF are unclear.

Noninvasive ventilation is commonly defined as adjunctive airway support in lieu of endotracheal intubation (ETI) and is used as either continuous positive airway pressure (CPAP) or intermittent biphasic positive airway pressure (BiPAP). ${ }^{3-5}$ It is pressure-controlled ventilation delivered by a mask that allows unrestricted spontaneous breathing any time in the ventilatory cycle. CPAP is delivered by a mask that completely covers the face, inclusive of both the nose and the mouth. BiPAP may also be administered by a full face mask, but also has the option of a delivery system that covers only the nasal passages, leaving the mouth open. CPAP provides expiratory support, whereas BiPAP provides inspiratory and expiratory support. With BiPAP, the patient must be able to coordinate their breathing cycle, closing their mouth during positive air pressure delivery; otherwise air will flow into the nares and out of the mouth, rather than being delivered to the lungs.

Noninvasive ventilation is used to provide temporary oxygenation and ventilation for respiratory distress and is not a definitive solution for airway control. As such, it is a temporizing alternative to immediate ETI and is used to provide time for other interventions (e.g., vasodilators for ADHF) to become effective. NIV is limited by the requirements of a mentally able and cooperative patient, with anatomy that allows an adequate facemask seal.

Since many small studies and anecdotal reports suggest benefit with NIV, it is commonly employed in the ED. ${ }^{6}$ Masip et al. ${ }^{1}$ evaluated NIV for ADHF. In this 15 study meta-analysis of 389 patients receiving NIV for acute pulmonary edema, mortality and the need for intubation were reduced. While meta-analyses may provide insight if the literature is without large data sets or randomized controlled trials, their weaknesses are well described, including that of Simpson's paradox ${ }^{7}$ (where an erroneous conclusion is reached due to an unknown variable).

The literature regarding outcomes of NIV for ADHF is not uniform. In a pooled systematic review of ADHF and NIV, Pang et al. ${ }^{8}$ reported that CPAP resulted in a $6.6 \%$ mortality decrease, but the confidence intervals (CIs) included a potential $3 \%$ mortality increase. Others have reported increased rates of ETI, acute myocardial infarction, and mortality when BiPAP is used in ADHF. ${ }^{9,10}$ Although limited by sample size, another meta-analysis pointed out that "weak evidence of an increase in the incidence of new myocardial infarction with bilevel ventilation versus CPAP was recorded." ${ }^{2}$ Most data were collected as one category, "use of bipap/cpap," so a distinction between the two cannot be made.

The largest analysis of the use of NIV in the ED for cardiogenic pulmonary edema is a 494-patient systematic review by Collins et al. ${ }^{11}$ Based on MEDLINE, The Excerpta Medica Database (EMBASE), and the Cochrane Library data from 1980 to 2005, they concluded that NIV is advantageous in ED patients with acute pulmonary edema. This pooled analysis concluded that when NIV is added to standard medical therapy, hospital mortality is reduced.

The purpose of our study was to determine patient outcomes associated with NIV and validate its safety compared to immediate ETI, using the large Acute Decompensated Heart Failure National Registry (ADHERE) database.

\section{METHODS}

\section{Study Design}

This analysis was a retrospective study from ADHERE. Participating sites were required to have institutional review board approval to have data entered into the registry. However, the data collection system was designed so that informed consent was exempted, as medical data were collected by retrospective chart review alone and did not include any protocol-specified treatment alteration. No patient identifiers were included in the data registry.

\section{Study Setting and Population}

The ADHERE protocol continuously collected data regarding the clinical characteristics, management, and outcomes of patients hospitalized for ADHF (Diagnostic-Related Group [DRG] 127) across the United States. As of January 2006, ADHERE included more than 280 participating hospitals, with data from more than 200,000 hospitalization episodes. Patients were eligible for inclusion into the ADHERE registry if they were at least 18 years old, admitted to an acute care hospital, and given a discharge diagnosis of acute heart failure (DRG 127), or if acute heart failure was the principal focus of treatment, and there was an accessible medical record. Eligibility was not contingent on the use of any specific therapeutic agent or regimen. Data were collected by retrospective chart review and entered into a Web-based data capture system via an electronic case report form. Investigators and research coordinators at individual sites identified patients and completed case report forms for all consecutive patients meeting the registry enrollment criteria. If a site had more than 75 enrollees per month, forms could be completed for a random sample of consecutive patients. The registry accumulated data on individual hospitalizations, not on individual patients.

Our study reviewed all hospitalized heart failure admissions admitted from the ED and entered into the ADHERE database. We compared characteristics and outcomes in the following cohorts: 1) no ventilation-did not receive either NIV or ETI; 2) NIV 
success-received NIV and did not require any additional airway support; 3) NIV failure-received a trial of NIV, but ultimately required ETI; and 4) ETI-individuals who received only ETI. The data were collected between October 2001 and November 2004.

\section{Study Protocol}

Data on demographics (age, gender, race), medical history (if the patient had any of 17 cardiovascular diseases), use of specific chronic medications (i.e., those recommended by the Heart Failure Society of America), clinical characteristics at initial presentation (e.g., vital signs, electrocardiogram, laboratory, and x-ray data), treatments received (e.g., any medication received in the ED or hospital for the treatment of heart failure), procedures performed (cardiopulmonary resuscitation [CPR], defibrillation, cardiac catheterization, dialysis, mechanical ventilation, or ultrafiltration), length of time and hospital admission, clinical response to therapy, and disposition were recorded using the information collected from the discharge medical record. Data are reported in aggregate format.

\section{Data Analysis}

The multivariable analysis included patients who received ventilation support. This included initial use of NIV, successful NIV use, unsuccessful NIV use and subsequent intubation, and initial ETI without an NIV trial. The goal of the study was not to identify the criteria that determined which patients received NIV versus ETI (once the decision was made to use ventilatory support); the focus was on successful NIV use and later to determine the association with additional heart failure treatments. Our study was not designed to find causal relationships.

One-way analysis of variance or two-sided Wilcoxon rank sum testing was performed for continuous data. Chi-square tests were used for categorical data. Multivariable logistic regression was used to adjust mortality comparisons in previously identified mortality risk factors $^{12,13}$ and variables shown to be significantly different between cohorts in the univariate analysis model. The area under the receiver operator curve (AUC) was used to assess model discrimination. Unadjusted and adjusted odds ratios along with their corresponding 95\% CI and p-values are reported. All analyses were performed using SAS Version 8.2 (SAS Institute, Cary, NC).

\section{RESULTS}

As of December 2004, the ADHERE database contained 147,362 records, with $114,756(78 \%)$ cases of $\mathrm{ADHF}$ admitted from the ED. Of ED patients, 37,372 (33\%) had procedure data, and ventilation was used in 2,430 $(6.5 \%)$. If ventilated, $1,760(72.4 \%)$ received NIV, and $670(27.6 \%)$ had ETI without an NIV trial. In the NIV cohort, 1,688 (95.9\%) were managed only by NIV (NIV success), while $72(4.1 \%)$ failed NIV and subsequently received ETI (NIV failure).

Demographics are presented in Table 1. The NIV failure group was younger and with more African Americans than all other groups. Data of past medical history are reported in Table 2. Higher rates of atrial fibrillation, COPD, and heart failure were reported in the NIV success group compared to the ETI group ( $p<0.05$ for all). More patients in the NIV failure group had liver failure; otherwise, there were no differences in past medical history compared to the ETI cohort.

Patients' initial hemodynamic data are presented in Table 3. NIV failures resembled the ETI group more than NIV successes. Only presenting oxygen saturation $\left(\mathrm{SaO}_{2}\right)$ was different between NIV failure and ETI, with the lowest level $(84 \%)$ in the NIV failure cohort and the highest in the NIV success $(90 \%)$ patients. Indices of volume overload were mixed between NIV success and ETI; there were no differences in chest $\mathrm{x}$-ray congestion rates, but edema and rales were more frequent, and dyspnea at rest less frequent, in the NIV success group. Although not statistically significant, NIV failures had a lower rate of abnormal troponin levels (7\% vs. 13\%) than the ETI group. The most predictive parameters for mortality (blood urea nitrogen [BUN], creatinine, and systolic blood pressure $[\mathrm{SBP}])^{12,13}$ were similar among all groups.

In regard to intravenous medications received during hospitalization, there was less difference between NIV failure and ETI than NIV successes and ETI (Table 4), suggesting an appropriate increase in therapeutic intensity for patients failing airway management. The NIV failure group received similar amounts of inotropes, but more vasodilators (nitroglycerin in particular) than patients in the ETI cohort. The NIV group received vasoactives (any inotrope or vasodilator) less often than ETI patients, except for nesiritide. Since urgency of treatment is important in dyspnea, it

Table 1
Demographics of the Study Groups

\begin{tabular}{|c|c|c|c|c|}
\hline & $\begin{array}{l}\text { No Ventilation } \\
\quad(n=34,942)\end{array}$ & $\begin{array}{l}\text { NIV Success } \\
(n=1,688)\end{array}$ & $\begin{array}{c}\text { NIV Failure } \\
(n=72)\end{array}$ & $\mathrm{ETI}(n=670)$ \\
\hline Age $(y r)$, mean $\pm S D$ & $72.7 \pm 14.2^{*}$ & $72.3 \pm 14.3^{*}$ & $68.3 \pm 14.0$ & $71.0 \pm 12.8$ \\
\hline Gender (\% male) & $48.3^{*}$ & 42.4 & 47.2 & 43.2 \\
\hline Race (\% African American) & $21.5^{*}$ & 23.3 & 31.4 & 25.7 \\
\hline Race (\% white) & $73.8^{*}$ & 73 & 61.4 & 69.6 \\
\hline
\end{tabular}


Table 2

Medical History of Patients in the Study Cohorts*

\begin{tabular}{|c|c|c|c|c|}
\hline Active malignancy & 5.2 & 6.5 & 4.2 & 5.4 \\
\hline CAD & 58.0 & 59.0 & 56.9 & 59.9 \\
\hline COPD/asthma & $31.1 \dagger$ & $45.0 \dagger$ & 43.1 & 39.4 \\
\hline Cardiac valvular disease & 21.5 & 18.8 & 18.1 & 19.6 \\
\hline Chronic dialysis & $4.7 \dagger$ & 6.1 & 5.6 & 6.7 \\
\hline History of HF & 75.5 & $80.3 \dagger$ & 80.6 & 75.2 \\
\hline Hyperlipidemia/dyslipidemia & 37.2 & 38.5 & 40.3 & 39.6 \\
\hline Hypertension & $75.8 \dagger$ & 79.4 & 81.9 & 80.0 \\
\hline Liver disease & 2.7 & 2.7 & $8.3 \dagger$ & 3.4 \\
\hline Pacemaker & $18.8 \dagger$ & $14.9 \dagger$ & 11.1 & 11.3 \\
\hline Peripheral vascular disease & 18.7 & 20.4 & 18.1 & 20.7 \\
\hline Prior MI & 29.5 & 32.5 & 26.4 & 31.6 \\
\hline
\end{tabular}

Table 3

Patient Characteristics on Initial Evaluation

\begin{tabular}{|c|c|c|c|c|}
\hline Congestion on first CXR (\%) & $73.9 *$ & 85.8 & 94.4 & 88.2 \\
\hline Edema (\%) & $66.0^{*}$ & $67.4^{*}$ & 66.7 & 56.7 \\
\hline Elevated troponin (\%) & $6.2 *$ & $7.0 *$ & 7.4 & 13.3 \\
\hline Fatigue $(\%)$ & $29.3^{*}$ & 28.9 & 30.6 & 25.1 \\
\hline Rales (\%) & $66.3^{*}$ & $78.8^{*}$ & 79.2 & 73.6 \\
\hline In- or pre-hospital LVEF, mean & 38.2 & $39.9 *$ & 36.5 & 36.9 \\
\hline $\mathrm{O}_{2}$ saturation, mean $\pm \mathrm{SD}$ & $94.2 \pm 5.9^{*}$ & $89.6 \pm 10.3^{*}$ & $84.0 \pm 15.7^{*}$ & $88.1 \pm 13.0$ \\
\hline $\mathrm{sBP}(\mathrm{mm} \mathrm{Hg})$, mean $\pm \mathrm{SD}$ & $143.7 \pm 32.4^{*}$ & $156.6 \pm 37.6$ & $157.0 \pm 38.7$ & $153.8 \pm 44.0$ \\
\hline $\mathrm{dBP}(\mathrm{mmHg})$, mean $\pm \mathrm{SD}$ & $77.5 \pm 19.8^{*}$ & $84.9 \pm 24.3$ & $88.4 \pm 26.0$ & $84.7 \pm 27.2$ \\
\hline $\mathrm{BUN}(\mathrm{mg} / \mathrm{dL})$, mean $\pm \mathrm{SD}$ & $32.1 \pm 20.9$ & $32.0 \pm 20.1$ & $30.8 \pm 20.6$ & $32.1 \pm 21.9$ \\
\hline Creatinine $(\mathrm{mg} / \mathrm{dL})$, mean $\pm \mathrm{SD}$ & $1.8 \pm 1.6^{*}$ & $1.9 \pm 2.0$ & $1.8 \pm 1.5$ & $2.1 \pm 2.2$ \\
\hline Sodium $(\mathrm{mmol} / \mathrm{L})$, mean \pm SD & $138.0 \pm 4.6$ & $138.2 \pm 4.5$ & $137.8 \pm 4.4$ & $138.4 \pm 5.0$ \\
\hline \multicolumn{5}{|c|}{$\begin{array}{l}\text { BUN = blood urea nitrogen; } C X R=\text { chest } x-r a y ; d B P=\text { diastolic blood pressure; } E T I=\text { endotracheal intubation; LVEF = left ventric- } \\
\text { ular ejection fraction; NIV = noninvasive ventilation; } s B P=\text { systolic blood pressure. } \\
{ }^{*} p<0.05 \text {. } p \text {-Values were calculated by one-way analysis of variance for continuous variables and chi-square test for categorical } \\
\text { variables, by comparing each category to ETI. }\end{array}$} \\
\hline
\end{tabular}

is noteworthy that there are no differences in time to vasoactives among the ventilation groups. However, both NIV success and NIV failures received intravenous diuretics faster than the ETI group (18 minutes vs. 36 minutes respectively).

Table 5 lists hospital procedures. Although not significantly different, NIV failures had less CPR, defibrillation, and dialysis than ETI. This observation continued with decreasing illness severity, becoming significant in the NIV success and no ventilation groups versus ETI.
In-hospital outcomes (Table 6) demonstrated stepwise mortality increases when comparing no ventilation or NIV to ETI. While no significant differences were found between NIV failure and ETI, there was a trend for increased length of stay (LOS) in NIV failures compared to ETI.

Table 7 compares outcomes between no ventilation and all NIV groups (successes and failures combined). No ventilation patients had a lower severity of illness, manifested by less premorbid medical history, higher 
Table 4

Intravenous Medications Received during Hospitalization

\begin{tabular}{|c|c|c|c|c|}
\hline Medication & $\begin{array}{l}\text { No Ventilation } \\
\quad(n=34,942)\end{array}$ & $\begin{array}{l}\text { NIV Success } \\
(n=1,688)\end{array}$ & $\begin{array}{c}\text { NIV Failure } \\
\quad(n=72)\end{array}$ & $\begin{array}{c}\text { ETI } \\
(n=670)\end{array}$ \\
\hline Any diuretics (\%) & $88.9 *$ & 92.9 & 94.4 & 92.1 \\
\hline Any vasoactives (\%) & $30.3^{*}$ & $52.4^{*}$ & 81.9 & 72.7 \\
\hline Any inotropes (\%) & $9.2^{*}$ & $11.9 *$ & 34.7 & 39.4 \\
\hline Dobutamine (\%) & $4.5^{*}$ & $4.6^{*}$ & 12.5 & 14.2 \\
\hline Dopamine (\%) & $4.8^{*}$ & $8.9 *$ & 27.8 & 30.4 \\
\hline Milrinone (\%) & $2.1^{*}$ & $1.4^{*}$ & 6.9 & 4.5 \\
\hline Any vasodilators (\%) & $25.0^{*}$ & $46.3^{*}$ & $68.1^{*}$ & 54.3 \\
\hline Nesiritide (\%) & $19.1 *$ & 25.1 & 29.2 & 28.5 \\
\hline Nitroglycerin (\%) & $7.3^{*}$ & $29.1 *$ & $45.8^{*}$ & 34.0 \\
\hline Nitroprusside (\%) & $0.5^{*}$ & $1.0^{*}$ & 5.6 & 3.6 \\
\hline Hours to first diuretic median & $2.6^{*}$ & $1.0^{*}$ & 0.7 & 1.3 \\
\hline Hours to first vasoactive, median & $5.5^{*}$ & 1.2 & 1.2 & 1.6 \\
\hline
\end{tabular}

Table 5

Procedures during Hospitalization

\begin{tabular}{|c|c|c|c|c|}
\hline Procedure & $\begin{array}{l}\text { No Ventilation } \\
(n=34,942)\end{array}$ & $\begin{array}{l}\text { NIV Success } \\
(n=1,688)\end{array}$ & $\begin{array}{l}\text { NIV Failure } \\
\quad(n=72)\end{array}$ & $\begin{array}{c}\text { ETI } \\
(n=670)\end{array}$ \\
\hline CPR & $0.9 *$ & $1.1^{*}$ & 5.6 & 11.2 \\
\hline Defibrillation & $0.7^{*}$ & $0.8^{*}$ & 0 & 4.0 \\
\hline Cardiac catheterization & $8.7 *$ & $8.8^{*}$ & 19.4 & 18.4 \\
\hline Dialysis & $6.1^{*}$ & 7.7 & 6.9 & 9.7 \\
\hline $\begin{array}{l}\text { Dialysis (begun during } \\
\text { index hospitalization) }\end{array}$ & $1.7^{*}$ & $1.9^{*}$ & 1.4 & 3.3 \\
\hline Ultrafiltration & 2.8 & 3.7 & 4.2 & 3.7 \\
\hline
\end{tabular}

$\mathrm{SaO}_{2}$, less evidence of pulmonary congestion, and less intravenous diuretics, vasodilators, and inotrope use. Consequently, the no ventilation cohort had shorter hospitalizations, fewer intensive care unit (ICU) admissions, and lower mortality, although median ICU time was slightly longer.

In-hospital deaths of NIV failure and ETI had similar unadjusted rates (Table 8). Even after risk adjustment, the mortality difference increased but did not reach statistical significance (multivariable logistic regression model AUC $=0.74$ ). Thus, the possibility of an adverse effect of NIV failure cannot be completely excluded. When comparing NIV success to ETI, even after adjustment for previously identified mortality risk factors, the NIV success cohort had significantly lower mortality.

\section{DISCUSSION}

To the best of our knowledge, this is the largest study of NIV in patients with ADHF to date. We report findings that more clearly define the population of $\mathrm{ADHF}$ patients likely to receive NIV and their corresponding outcomes compared to other patient cohorts. We found that NIV is a commonly used intervention, and ADHF patients selected for NIV are usually successfully managed, as suggested by not requiring ETI. A small minority of patients who received NIV ultimately required ETI $(72 / 1,760 ; 4.1 \%)$. Our data therefore suggest that NIV is an effective strategy in the treatment of ADHF.

Endotracheal intubation in hypoxic, critically ill, hemodynamically unstable patients can be risky. This is suggested by the fact that those undergoing immediate ETI suffered the highest mortality of any group in our analysis. An alternative, safer, and effective management strategy is desirable. In this study, we describe a trend of worsening outcomes, starting with the lowest death rate in the no ventilation group, increasing through both NIV groups, and highest in ETI cohort. Our findings are inconsistent with prior studies suggesting that NIV is potentially harmful in the setting of ADHF. ${ }^{8-10,14}$

Several theoretical concerns have been proposed with NIV in addition to the inherent risk of barotrauma from all types of positive pressure ventilation. With elevated intrathoracic pressure, increased resistance to ventricular ejection occurs. This is probably of little consequence in the normal heart, but in a failing myocardium, an increased workload can decrease cardiac output. For example, in atrial fibrillation treated with CPAP, a decline in left ventricular ejection fraction (LVEF), especially in the setting of low systemic vascular resistance (SVR), occurs. ${ }^{14}$ This suggests that the hemodynamic impact of NIV in ADHF may be significant. 
Table 6

Outcomes

\begin{tabular}{|c|c|c|c|c|}
\hline Mortality (\%) & $3.2^{*}$ & $7.9^{*}$ & 13.9 & 15.4 \\
\hline Median ICU LOS (days) & $2.3^{*}$ & $2.0^{*}$ & 3.2 & 3.1 \\
\hline Median hospital LOS (days) & $4.2^{*}$ & $4.6^{*}$ & 8.1 & 6.5 \\
\hline Discharged asymptomatic (\%) & 46.0 & 46.4 & 40.7 & 43.1 \\
\hline \multicolumn{5}{|c|}{$\begin{array}{l}\mathrm{ETI}=\text { endotracheal intubation; ICU = intensive care unit; } \mathrm{LOS}=\text { length of stay; NIV = noninvasive ventilation. } \\
{ }^{*} \mathrm{p}<0.05 . \mathrm{p} \text {-Values were calculated by Wilcoxon test for continuous variables and chi-square test for categorical variables, by } \\
\text { comparing each category to ETI. }\end{array}$} \\
\hline
\end{tabular}

\section{Table 7}

No Ventilation versus Noninvasive Ventilation (NIV)

\begin{tabular}{|c|c|c|}
\hline & $\begin{array}{l}\text { No Ventilation } \\
(n=34,942)\end{array}$ & $\begin{array}{c}\text { NIV } \\
(n=1,760)\end{array}$ \\
\hline \multicolumn{3}{|l|}{ Medical history } \\
\hline Active malignancy & 5.2 & $6.4^{*}$ \\
\hline Atrial fibrillation & 31.9 & $27.5^{*}$ \\
\hline COPD/Asthma & 31.1 & $44.9 *$ \\
\hline Cardiac valvular disease & 21.5 & $18.8^{*}$ \\
\hline Chronic dialysis & 4.7 & $6.1^{*}$ \\
\hline Chronic RI & 30.3 & $33.0 *$ \\
\hline Diabetes & 44.4 & $50.2 *$ \\
\hline History of HF & 75.5 & $80.3^{*}$ \\
\hline Hypertension & 75.8 & $79.5^{*}$ \\
\hline Pacemaker & 18.8 & $14.8^{*}$ \\
\hline Prior Ml & 29.5 & $32.3^{*}$ \\
\hline \multicolumn{3}{|l|}{ Signs of congestion } \\
\hline CXR with congestion & 73.9 & $86.2^{*}$ \\
\hline Rest dyspnea & 31.9 & $57.4^{*}$ \\
\hline Rales & 66.3 & $78.8 *$ \\
\hline \multicolumn{3}{|l|}{ Presentation findings } \\
\hline $\mathrm{sBP}(\mathrm{mm} \mathrm{Hg})$, mean & 143.7 & $156.7^{*}$ \\
\hline Initial $\mathrm{O}_{2}$ saturation (\%), mean & 94.2 & $89.4^{*}$ \\
\hline Creatinine $(\mathrm{mg} / \mathrm{dL})$, mean & 1.8 & $1.9 *$ \\
\hline HR (beats/min), mean & 87.4 & $99.8^{*}$ \\
\hline \multicolumn{3}{|l|}{$\begin{array}{l}\text { IV medications during } \\
\text { hospitalization }\end{array}$} \\
\hline Diuretics & 88.9 & $93.0 *$ \\
\hline Inotropes & 9.2 & $12.8^{*}$ \\
\hline Vasodilators & 25.0 & $47.2 *$ \\
\hline Median time to diuretic (hr) & 2.6 & $1.0^{*}$ \\
\hline $\begin{array}{l}\text { Median time to first } \\
\text { vasoactive (hr) }\end{array}$ & 5.5 & $1.2^{*}$ \\
\hline \multicolumn{3}{|l|}{ Hospital procedures/outcomes } \\
\hline Dialysis & 6.1 & $7.7^{*}$ \\
\hline Median hospital LOS (days) & 4.2 & $4.8^{*}$ \\
\hline Admitted to ICU (\%) & 13.0 & $40.9 *$ \\
\hline Median ICU time (days) & 2.3 & $2.1^{*}$ \\
\hline Mortality (\%) & 3.2 & $8.1^{*}$ \\
\hline \multicolumn{3}{|c|}{$\begin{array}{l}\text { COPD = chronic obstructive pulmonary disease; } \mathrm{CXR}=\text { chest } \\
\mathrm{x} \text {-ray; } \mathrm{HF}=\text { heart failure; } \mathrm{HR}=\text { heart rate; } \mathrm{ICU}=\text { intensive care } \\
\text { unit; IV = intravenous; LOS = length of stay; } \mathrm{MI}=\text { myocardial } \\
\text { infarction; NIV = noninvasive ventilation; RI= renal insuffi- } \\
\text { ciency; } \mathrm{sBP}=\text { systolic blood pressure. } \\
{ }^{*} \mathrm{p}<0.05 \text {. p-Values were calculated for continuous variables } \\
\text { by one-way analysis of variance or Wilcoxon test and for } \\
\text { categorical variables by a chi-square test. All values are } \\
\text { percentages unless otherwise noted. }\end{array}$} \\
\hline
\end{tabular}

Normally, a decline in cardiac output is compensated for by neurohormonally mediated increases in SVR. This is well tolerated in normal hearts; in heart failure
Table 8

Multivariable Model Results



(HF), increased SVR further exacerbates the cardiac output deficit. Carbon dioxide retention leads to respiratory acidosis with the potential for adverse cardiac effects. Ultimately, increasing SVR causes a decrease in cardiac output, which triggers reflexive SVR increases and further decreased cardiac output occurs. If untreated, this spiral ends with cardiogenic shock and death. One trial of 40 patients compared BiPAP and low-dose isosorbide dinitrate (NIV group) to high-dose isosorbide dinitrate (no NIV group). ${ }^{10}$ NIV patients had higher rates of ETI and death, lower $\mathrm{SaO}_{2}$, and higher composite endpoints of death, myocardial infarction (MI), or ETI. Another analysis comparing BiPAP and CPAP was terminated early because of a marked increase in the rate of MI in the BiPAP cohort. Unfortunately, the major limitation of this study was that it lacked a standard therapy cohort. ${ }^{15}$

In contrast to these reports, two recent meta-analyses of NIV in ADHF suggest a potential benefit. Although neither analysis exceeds 300 patients, several unproven theories support their conclusions. These include the fact that positive pressure improves oxygenation by increasing the numbers of expanded alveoli, the fact that increased intraalveolar pressure physically drives fluid into capillaries across alveolar membranes (thus improving pulmonary gas exchange), the fact that by using NIV the work of breathing is decreased, and the fact that increasing intrathoracic pressure decreases venous return and cardiac filling pressures. 
In our analysis, a therapeutic trial of NIV produced no worse outcomes than immediate ETI in terms of mortality, ICU LOS, overall hospital LOS, or asymptomatic discharge. However, although statistically insignificant, the median hospital LOS was longer for NIV failures. There was a nonsignificant increase in mortality in the NIV group.

In examining the LOS, several trends are apparent. Patients receiving no NIV had lower rates of ICU admissions, but if admitted to the ICU, had a longer LOS than those receiving NIV. Why this occurs is unclear, but may be related to the consequence of unclear initial presentations resulting in therapeutic delays or acute decompensation occurring after hospitalization. Also unexplained is the nonsignificant trend for patients receiving NIV and ETI requiring longer overall LOS than the cohort undergoing ETI only. Although early death in the ETI cohort could have explained these results, the median LOS for patients alive at discharge showed similar trends (8.8 days vs. 6.9 days for NIV failure vs. ETI, $\mathrm{p}>0.05$, respectively).

Our results suggest several clinical opportunities. Acute pulmonary edema with severe respiratory distress can be transient, representing an imbalance of hemodynamics rather than pure volume overload. In this situation, aggressive ED management with therapy directed at correcting the mismatch between excessive SVR and decreased cardiac output may allow sufficient time for some patients to improve. This is supported by data from several risk stratification analyses; patients with the highest presenting blood pressures were most likely to have successful management (defined as discharge within 24 hours and no rehospitalization within 30 days). ${ }^{16,17}$ By temporarily obviating the need for ETI, a short course of NIV may improve outcomes by allowing hemodynamic interventions (such as lowering blood pressure) time to become effective. NIV is not definitive therapy, but is a temporizing measure to avoid ETI while initiating definitive therapy. It is possible that if used with inadequate ${ }^{10}$ or absent concomitant medical therapy, NIV outcomes could be worse than ETI alone.

To the best of our knowledge, we present data from the largest cohort of NIV and ADHF patients to date and suggest that in selected patients, it is reasonable to attempt a closely monitored trial of NIV prior to ETI. If unsuccessful, ETI may proceed without significantly worsening outcomes beyond that expected from immediate ETI. However, it is important to note that a significant number of patients in this analysis were deemed to require immediate ETI $(28 \%$ of patients on respiratory support), and we cannot comment on the value of NIV in this cohort. In the absence of specific recommendations, selection of patients most likely to be successfully treated with NIV is based on clinical judgment. Our data show that if it was possible to avoid immediate ETI in ADHF, patients receiving NIV had significantly better outcomes, with lower rates of cardiopulmonary resuscitation and defibrillation, decreased ICU LOS, and fewer deaths. Beyond the existing small studies that were not powered to demonstrate small mortality trends, the size of this observation database provides reassurances that NIV is not associated with increased mortality in patients with ADHF.

\section{LIMITATIONS}

This analysis is an examination of a large retrospective data set and cannot determine cause and effect. It is important to recognize that physicians apply a selection bias when choosing NIV or immediate ETI for ADHF. The small number of NIV failures (less than $5 \%$ ) is consistent with a high degree of accuracy in selecting the appropriate patient. We must also note that a significant number of patients required immediate ETI $(28 \%)$, and we cannot comment on the value of NIV in this cohort. Additionally, although it appears that ETI patients had a greater severity of illness, as judged by the increased risk of adverse outcomes, we cannot ascertain if the selection of patients for immediate ETI was accurate or appropriate. Some who received immediate ETI may have been successfully managed with NIV. However, with the suggestion that a trial of NIV did not significantly increase risk in ADHF, a prospective analysis to determine if NIV improves outcomes can be reasonably performed.

Alternatively, our results could potentially be biased by the consequence of a decreased severity of illness in the NIV success cohort, where physicians used NIV in patients who did not require it. This is not supported by the demographic, initial presentation, or chronic treatment data (Tables $1-5$ ). While there were significant differences in the medical history, four of the five parameters were actually worse in the NIV success cohort, compared to ETI. Furthermore, in another ADHERE analysis examining findings associated with acute mortality, an initial BUN $>43 \mathrm{mg} / \mathrm{dL}$, $\mathrm{sBP}<115 \mathrm{~mm} \mathrm{Hg}$, or creatinine exceeding $2.7 \mathrm{mg} / \mathrm{dL}$ was the most important predictor of death; ${ }^{12,13}$ there was no difference between the NIV success and the ETI groups. Finally, while troponin elevation has been reported to be more prevalent in NIV ${ }^{10,15}$ our analysis found it elevated more often in the ETI group.

Of patients failing NIV, duration of therapy was variable due to subjective judgment by the provider. The timing of actual initiation of NIV or ETI was not fixed and was at the discretion of the treatment physician. This makes timing a limitation. Furthermore, patients captured in this study were in different locations in the hospital, not just localized to the ED or observation unit. Procedures were done in the ED, and there are no available details on specific timing or duration.

This study describes the overall pattern of ventilatory support used in ADHF patients in the ADHERE centers. There is no attempt to describe the indications used to determine use of any therapy, including ventilatory support. Thus, based on our data, it is inappropriate to conclude that any specific treatment options are more or less safe or more or less effective than another.

\section{CONCLUSIONS}

Noninvasive ventilation is an airway adjunct that may be useful in heart failure patients with severe respiratory distress and dyspnea. When used in selected individuals, it is frequently successful at avoiding ETI. Furthermore, in those successfully managed with NIV, outcomes may be better than in patients undergoing 
immediate ETI. Although caution should be utilized in patient selection, NIV may be a reasonable treatment option in ADHF.

\section{References}

1. Masip J, Roque M, Sanchez B, et al. Noninvasive ventilation in acute cardiogenic pulmonary edema: systematic review and meta-analysis. JAMA. 2005; 294:3124-30.

2. Peter JV, Moran JL, Phillips-Hughes J, Graham P, Bersten A. Effect of non-invasive positive pressure ventilation (NIPPV) on mortality in patients with acute cardiogenic pulmonary oedema: a meta-analysis. Lancet. 2006; 367:1155-63.

3. Rasanen J, Heikkila J, Downs J, Nikki P, Vaisanen I, Viitanen A. Continuous positive airway pressure by face mask in acute cardiogenic pulmonary edema. Am J Cardiol. 1985; 55:296-300.

4. Bersten AD, Holt AW, Vedig AE, Skowronski GA, Baggoley CJ. Treatment of severe cardiogenic pulmonary edema with continuous positive airway pressure delivered by facemask. N Eng J Med. 1991; 325:1825-30.

5. Lin M, Yang YF, Chiang HT, Chang MS, Chiang BN, Cheitlin MD. Reappraisal of continuous positive airway pressure therapy in acute cardiogenic pulmonary edema. Short-term results and long-term follow-up. Chest. 1995; 107:1379-86.

6. Pelosi P, Severgnini P, Aspesi M, et al. Non-invasive ventilation delivered by conventional interfaces and helmet in the emergency department. Eur J Emerg Med. 2003; 10:79-86.

7. Heydtmann M. Simpson's Paradox and the limits of statistical data. Q J Med. 2002; 95:247-9.

8. Pang D, Keenan SP, Cook DJ, Sibbald WJ. The effect of positive pressure airway support on mortality and the need for intubation in cardiogenic pulmonary edema: a systematic review. Chest. 1998; 114:1185-92.
9. Levitt MA. A prospective, randomized trial of BiPAP in severe acute congestive heart failure. J Emerg Med. 2001; 21:363-9.

10. Sharon A, Shpirer I, Kaluski E, et al. High-dose intravenous isosorbide-dinitrate is safer and better than Bi-PAP ventilation combined with conventional treatment for severe pulmonary edema. J Am Coll Cardiol. 2000; 36:832-7.

11. Collins SP, Mielniczuk LM, Whittingham HA, Boseley ME, Schramm DR, Storrow AB. The use of noninvasive ventilation in emergency department patients with acute cardiogenic pulmonary edema: a systematic review. Ann Emerg Med. 2006; 48:260-9.

12. Fonarow GC, Adams KF Jr, Abraham WT, et al. Risk stratification for in-hospital mortality in acutely decompensated heart failure: classification and regression tree analysis. JAMA. 2005; 293:572-80.

13. Abraham WT, Adams KF, Fonarow GC, et al.; ADHERE Scientific Advisory Committee and Investigators; ADHERE Study Group. In-hospital mortality in patients with acute decompensated heart failure requiring intravenous vasoactive medications: an analysis from the Acute Decompensated Heart Failure National Registry (ADHERE). J Am Coll Cardiol. 2005; 46:57-64.

14. Calverley PM. Nasal CPAP in cardiac failure: case not proven. Sleep. 1996; 19(10 Suppl):S236-9.

15. Mehta S, Jay GD, Woolard RH, et al. Randomized, prospective trial of bilevel versus continuous positive airway pressure in acute pulmonary edema. Crit Care Med. 1997; 25:620-8.

16. Diercks DB, Kirk JD, Peacock WF, Weber JE. Identification of emergency department patients with decompensated heart failure at low risk for adverse events and prolonged hospitalization. J Card Fail (Suppl) 2004; 10:S118.

17. Burkhardt J, Peacock WF, Emerman CL. Predictors of emergency department observation unit outcomes. Acad Emerg Med. 2005; 12:869-74. 